\title{
THE ROLE OF CITIZENS IN SETTING THE VISIONS FOR MISSION-ORIENTED RESEARCH AND INNOVATION ${ }^{1}$
}

\author{
JULIEN CHICOT AND ALBERTO DOMINI
}

DOI: $10.22163 /$ fteval.2019.329

\section{ABSTRACT}

$\mathrm{H}$ orizon Europe aims to orient EU research and innovation policy towards bold and ambitious missions and to engage, as part of this process, a wide range of stakeholders. In presuming that the approach to public participation in policy-making is linked to the characteristics of each mission-oriented R\&l initiative, this paper aims to investigate the role of citizens in the definition of missions and thus in building the (input and output) legitimacy of the related initiatives. On the one hand, a large sample of case studies provides evidence of the practices of citizen involvement in vision-setting and demonstrates that they are still primarily aimed at ensuring citizens' buy-in rather than involving them genuinely in the definition of missions. On the other hand, findings from stakeholder interviews and an expert workshop shed light on the challenges in engaging citizens in decision-making: besides designing an efficient procedure, the role of citizens in respect to other stakeholders should be clearly identified. Even though low involvement of citizens in vision-setting did not seemingly affect the effectiveness of most of the mission-oriented initiatives investigated, further efforts for engaging them in decision-making should be made in the light of the increasing complexity of challenges and the perceived democracy gap in Europe.

\section{INTRODUCTION}

Political upheavals in recent years are symptoms of a significant and widening divide between politicians and their electorate, between the rulers and the ruled. With the exponential increase in the use of social media, participation and representation are acquiring new forms and pose new challenges to the functioning of even the most consolidated democracies. In a context where large parts of the population have access to education and information, decision-making does not any longer appear as the exclusive prerogative of the so-called 'establishment'. The views according to which elected officials take policy decisions while citizens express themselves only during elections are highly contested. Public institutions and especially those of the European Union, should keep up with this new phenomenon and demonstrate their good intentions to adapt to the new circumstances and address this democratic gap.

This trend is not a new phenomenon. Since the 1990s, if not before, democratic deficits and social exclusion have been in the spotlight (the democratic deficit of the European Union has been a topic of EU affairs already for a long time) and bottom-up policy-making mechanisms engaging citizens, such as participatory budgeting, have been experimented. By opening the decision-making process to external stakeholders, policymakers expect to reduce conflicts and favour societal acceptance of their decisions. In a context of a growing demand for transparency and participatory policy-making, policy evaluation should consider legitimacy, alongside other criteria such as effectiveness and efficiency.

These 'citizens' refer to individuals belonging to a social community ruled by recognised bodies and institutions. This broad definition embraces a wide array of actors, who may sometimes act, as individual experts or market actors. Despite this potential confusion between citizens and other categories of stakeholders, their distinction is especially relevant in the analysis of bottom-up policy-making. Unlike other actors, citizens should be involved to reflect on problems and potential policy responses based on the societal needs and values of the community to which they belong. While not neglecting the contribution of people when acting as services users, consumers of goods or individual experts, this research considers bottom-up approaches in policy-making as those allowing the involvement of citizens (also called hereafter 'common' and 'ordinary people').

Current trends in research and innovation (RGI) policy at the EU and national levels have given a renewed impetus to citizen engagement in policy-making. In June 2018, the European Commission proposed that "missions" form part of the future Ninth EU Framework Programme for

The authors wish to thank their colleagues in the Joint Institute for Innovation Policy (JIIP) and especially Jacqueline Allan and Robbert Fisher for their support in this endeavour and their valuable comments.

This research draws on two studies conducted for the European Commission (Directorate General for Research \& Innovation) in the context of services contracts (30-CE-0880718/00-38 and 30-CE-0883606/0035) for the preparation of Horizon Europe. Both studies were coordinated by JIIP and involved its four members (Joanneum Research, Tecnalia, TNO and VTT) as well as the Danish Technological Institute (DTI) and Valdani Vicari and Associati (VVA). The views expressed in this paper are nevertheless exclusively those of the authors and do not reflect the position neither of JIIP and its members nor of the European Commission. 
Research and Innovation, Horizon Europe. Following this approach, the EU RYI policy will increasingly concentrate efforts on the development and, in some circumstances, diffusion of new solutions to identified problems, and thereby on the achievement of ambitious goals. Missions would typically present clearly defined targets to be achieved within a specific timeframe, so progress can be measured against predefined milestones. While public administrations remain the main policy-makers, private organisations, such as businesses and foundations, have been also very active in identifying missions critical to them and their communities, most often with the support of public administrations (JIIP et al., 2018a).

Mission-oriented R\&l initiatives may be divided into two broad categories depending on the nature of their goals: (1) programmes focused on achieving a single well-defined objective, often of scientific or technological nature (e.g. accelerating the development of a solar-powered aircraft able to revolutionise air transport), and (2) far-reaching initiatives aimed at (or implying) the transformation of systems to address complex challenges (also known as societal and/or transformative missions, e.g. climate change or the ageing society).

The orientation of Ryl policy towards missions inherently requires that a vision is defined beforehand and that the actions of all relevant stakeholders are coordinated accordingly (Weber and Rohracher, 2012). Missions relate to complex challenges that isolated (traditional) policymakers may have difficulty in grasping. Furthermore, their achievement may have large impacts affecting many actors. Due to this orientation, they are also more likely to be highly visible to citizens and therefore more sensitive to societal acceptance. Therefore, the main objectives of engaging actors other than traditional decision-makers are to ensure that the selected missions address the most pressing needs and that legitimate initiatives will result. For these reasons, full top-down approaches in the definition of visions for orienting Ryl policies and efforts are raising growing criticism, and research on the rationales for, and the modalities of, citizen involvement in the development of missions, and in co-creating a vision for future R\&l policies, becomes crucial.

The current work aims to contribute to an understanding of the relevance of an open approach to policy-making in the specific area of mission-oriented R\&l, by distinguishing different levels of citizen involvement in the current practices, and the challenges that their implementation entails. By focusing on the rationales for citizen involvement and on the modalities in which this has been displayed, our research also aims to investigate the level of legitimacy that the general public entrusts, according to its societal values and needs, in the process leading to the launch of these broad policy interventions (input legitimacy) and in the pursued outcomes (output legitimacy) (Boon and Edler, 2018).

After an outline of the literature on the role of citizens in policy-making (Section 1) and the description of the methodology employed to gather evidence (Section 2), this paper proceeds in identifying the most common practices of citizen involvement observed in the vision-setting of mission-oriented Ryl initiatives (Section 3). To complete the analysis, the impressions of stakeholders from academia, public administrations and industry help characterise three main challenges that policy-makers and researchers encounter in examining citizen involvement (Section 4). Finally, Section 5 concludes and provides the EU policy-makers with some recommendations.

\section{ROLE OF CITIZENS IN POLICY- MAKING AND MODALITIES OF THEIR ENGAGEMENT}

\subsection{THE ROLE OF CITIZENS IN POLICY-MAKING}

Policy-making is the process by which the responsible authorities determine an appropriate course of action to solve a problem and address an opportunity for their target group. It takes place in an environment which influences it (Flanagan and Uyarra, 2016), with stakeholders that range from recipients and providers of the solution (for a problem) and may include other interested parties (e.g. philanthropists or lobbyists). For these reasons, policy-making processes vary widely depending on the national, regional, sectoral or technological systems in which they occur. For the sake of clarity, they can be divided into three stages (Edquist, 2011): (i) setting the vision, i.e. defining the problem to be solved; (ii) identifying the causes of the problem and translating them into recognisable objectives and into sets of smaller, achievable and measurable goals; and, (iii) selecting the policy instruments. The visions that set the direction for policy interventions relate to problems that are considered social constructs. Their definition is influenced by a number of contingencies (Laranja, Uyarra and Flanagan, 2008) and has a political dimension that should not be overlooked (Borrás and Edquist, 2013).

Policy-making is a process orchestrated by the responsible authorities but with the concurrent intervention of a wide range of actors seeking recognition for their respective needs, and their inclusion in the policy agenda. These 'policy entrepreneurs' (Kingdon, 1984) may consist of industry and other interest groups, as well as individuals and citizens. Traditionally, policy-makers have been the elites, i.e. the dominant groups within specific communities, assuming and maintaining positions of power in governmental institutions as well as social movements (often under organised and militant minorities) that enforce their own thematic agendas. Citizens have been maintained in passive roles delegating their voice to elected representatives (convinced that further public participation could disrupt the functioning of public administrations) or being customers of public services (Vigoda, 2002).

The profound economic, demographic and social changes that emerged in most, if not all, OECD countries in the post-war period have led to a growing demand for the opening up of policy-making processes to public participation (OECD 2001). Since then, mechanisms - increasingly supported by the digitalisation of public services and social media - have been granting citizens the opportunity to mobilise, organise and influence priority setting. Increasing efforts have been made to improve access to public information (including explanations of the choice of the employed instruments). Policy-makers may also ask citizens, through a consultative process, to reflect on their decisions and to provide feedback and additional insights. Such actions may be used to support the selection of missions and associated policy instruments. Finally, citizens may be engaged earlier in the process to shape social and policy dialogues and identify the most pressing challenges, the missions and related policy interventions.

Nevertheless, the involvement of citizens in policy-making does not mean that they replace the public authorities in their role of designing and implementing policies. Formal policy formulation remains in the 
hands of traditional policy-makers, who should not be confused with 'policy entrepreneurs'. The paucity of citizen involvement is especially prominent in R\&l policy, where it is believed that researchers should benefit from full freedom in the direction of their research (Bush, 1945). The emergence of mission-oriented R\&I increases these tensions within the policy-making process between 'policy entrepreneurs' and traditional policy-makers and, more specifically, between the need to involve of a wide range of actors, to define the most relevant visions, and the need for leadership (as opposed to a self-organising process), to guide system transition (Bugge et al., 2018).

\subsection{THE RATIONALES FOR CITIZEN INVOLVEMENT IN VISION-SETTING}

Directionality is a core and differentiating feature of mission-oriented R\&I policy (Weber and Rohracher, 2012), which implies the definition of a vision that will guide policy interventions towards the solution of identified problems. Because these problems are complex and "wicked" when they are linked to socio-economic challenges (Nelson, 2011), policy-makers may require, for their better understanding, knowledge from external stakeholders such as citizens.

Efforts to involve citizens in policy-making have increased also in response to their growing demand for transparency, accountability and participation (OECD, 2001). They are expected to have a direct and positive influence on the legitimacy of policy decisions, i.e. on their level of societal acceptance and (implicit) popular support. According to Dahl's definition (1998), legitimacy has to do with a "general confidence among the public that a government's power to make binding decision for the polity are justified and appropriate" (cited by Wallner, 2008, p. 422). Given that there is no universal criterion to assess whether, and to which degree, a policy measure is legitimate, such a functional definition of legitimacy highlights its subjective nature: it primarily relies on perceptions about the beliefs of individuals and groups.

Legitimacy is not static but varies throughout the policy cycle as the perceptions of, and popular support for, policy measures may vary during their implementation. However, even though opportunities for citizen participation may arise at any stage of this cycle, this research contends that policy-makers should pay particular attention to the engagement of citizens in vision setting. Indeed, the initial level of legitimacy has significant influence on the subsequent phases of the policy cycle (Jagers et al., 2016). Furthermore, a legitimate vision may ensure directionality of mission-oriented R\&I initiatives and therefore reduce the risk of policy failure (Wallner, 2008).

Legitimacy has two dimensions: input legitimacy and output legitimacy (Boon and Edler, 2018). Input legitimacy designates the societal acceptance of the process through which needs are transformed into policy problems and the instruments to solve them are defined. It is influenced by the level of openness to stakeholders other than the traditional policy-makers, the efficiency of the process, as well as its transparency. Output legitimacy refers to the situation in which policies are societally accepted and supported by citizens because their outcomes are seen to contribute to addressing perceived societal needs (Scharpf, 2006).

Output legitimacy has traditionally been considered to be the most significant component of the overall legitimacy of policy measures. In other words, citizens may give their support to policy decisions, whose targeted outputs are in line with their needs and expectations (output legitimacy), even though they do not perceive the process, through which these decisions have been developed, as fully fair (e.g. as they were excluded from it) (Boedeltje and Cornips, 2004). Nevertheless, in the current context of growing criticism of the representative democratic model, the perception of fairness in policy-making should not be overlooked and top-down decision-makers must design and follow policy-making processes that satisfy citizens' expectations. Otherwise, R\&l policy - particularly if mission-oriented - may fail.

\section{METHODOLOGY}

To investigate the engagement of citizens in setting the direction for, and building the legitimacy of, of mission-oriented R\&l, evidence was drawn from two studies on mission-oriented Rql policy to support the European Commission in the preparation of Horizon Europe (JIIP et al., 2018a; JIIP et al., 2018b). The materials include a series of case studies (identified based on a global policy mapping), interviews with R\&l stakeholders, and a final workshop with experts and stakeholders.

The current work uses multiple case studies to compile compelling and robust evidence for supporting the analysis of mechanisms (i.e. their rationales, context and instruments) to engage citizens in setting visions for mission-oriented Ryl policy. 53 out of 140 identified mission-oriented Ryl initiatives in the European Union, its 28 Member States and some of its main competitors ${ }^{1}$ were analysed ${ }^{2}$. This selection takes into account their geographical and thematic coverage, whether they are public or private initiatives, the type of challenge they target (accelerators or transformers), their level of intervention (i.e. international, national, regional or local), and their scale. Information on their overall context, policy instruments, governance, drivers and level of engagement of citizens and stakeholders was collected ${ }^{3}$ to ease their comparison.

To understand, based on these case studies, the practices used to engage citizens in the direction-setting process for mission-oriented Rql initiatives, the relevant information was identified and coded. It was firstly determined whether and how citizens were engaged; the timing of their engagement; and the instruments employed. Information was collected, where available, on the rationales for citizen engagement and complemented by desk research. A broad definition of citizens, including civil society organisations, was adopted. Even though no causal relationship between any feature of mission-oriented R\&l initiatives and the degree of citizen engagement in vision-setting can be identified based on this methodology, the coding adopted enables a better understanding of such practices.

The case studies were complemented with insights from researchers, policy-makers (including EU agencies, national governments, local authorities and national research and innovation agencies), representatives of industry and of civil society organisations. Their perceptions of the challenges of, and solutions for, a higher level of engagement of citizens in the vision-setting process for mission-oriented RGI initiatives were collected by means of a series of interviews ${ }^{4}$, and an expert and stakeholder workshop ${ }^{5}$. Their findings allow to flesh out the existing tensions between the need to have a clear orientation and directionality and the willingness to involve a wide array of stakeholders including citizens for improving the legitimacy of the policy interventions under consideration. 


\section{PRACTICES OF CITIZEN ENGAGEMENT IN VISION-SETTING}

\subsection{ABSENCE OF MECHANISM TO INVOLVE CITIZENS IN VISION-SETTING}

A substantial share of the mission-oriented R\&l initiatives analysed do not present any evidence of citizen involvement in the decision on their visions. These initiatives present some characteristics that may explain a perceived reluctance in engaging citizens.

The first explanation of a lack of public participation mechanisms is the high technological component of the missions. In these cases, decision-makers do not adopt an open approach either because they consider the contribution of citizens as hampering the fulfilment of their ultimate objectives or because they deem it irrelevant. To set such visions, there is no perceived need to involve other actors than knowledgeable experts or stakeholders in the relevant domains, e.g. governmental institutions, industrial representatives, technicians or scientists. No actions are therefore needed to inform citizens or involve them in decision-making, as, due to their low or lack of skills, they will not be able to make any valuable contribution. An example of such an approach is the development of the E-Fan electric aircraft. This technology-driven initiative, initiated and implemented by a consortium of private organisations, was conceived in a pure top-down manner in consultation with a few partners from several national and regional institutions, but without input from the general public, neither any active communication campaign nor participative mechanisms. In the view of the initiators of this initiative, the expertise and the feedback provided by experts and stakeholders in the aerospace and air transport sectors were sufficient to orient research efforts towards the development of a zero-emission aircraft. No clear evidence of actions aiming at increasing legitimacy of this endeavour among the general public has been found.

The absence of citizen engagement in vision-setting may also be explained by the qualities of their initiators. Desk research brings evidence that private (profit-oriented) companies ${ }^{6}$ are less keen on involving citizens than public bodies pursuing societal goals. Given that businesses do not have a mandate (or the presumption) to deliver solutions to meet societal demands expressed by citizens, they do not feel accountable vis-à-vis the general public. For this reason, they tend to determine their missions in full autonomy without comments from citizens, preferring to rely on stakeholders with a recognised expertise and/or potential users. This approach is reflected, for instance, in the development of the panEuropean aircraft manufacturer, Airbus. The governments that contributed to its inception did not involve citizens in setting up the objectives of this mostly technology-driven and commercial endeavour. The relevance and durability of this commitment to building a European aerospace consortium able to compete with US counterparts was not subject to either public consultations or an active communication strategy aimed at increasing its legitimacy.

Some public authorities share with private companies a strong reluctance in involving citizens in the development of policy interventions. Even in consolidated and longstanding democracies, both the govern- ment and the general public might indeed accept that a distance is maintained between them. This situation can be observed, for instance, in democratic regimes whose culture focuses more on the social role of communities than that of individuals (e.g. Japan) and/or whose policymaking practices are still heavily influenced by the legacy of preceding authoritarian regimes. The absence of citizen involvement in the e-Estonia initiative can be interpreted along these lines. Although this initiative, launched few years after the dissolution of the Soviet Union, aims to transform public services through their digitalisation and to enable more open policy-making mechanisms, the legacy of the Communist regime led the institutions to lack the necessary habit to engage citizens in the definition of these objectives and the overall vision of R\&l policies.

The third explanation for the lack of citizen engagement is the fact that the public bodies that initiate the concerned mission-oriented Ryl initiatives do not operate on the basis of democratic rules and do not therefore feel the need to be responsive to public needs and demands. This is the case of authoritarian regimes, where decision-makers are not democratically accountable. Here, the mission-oriented Ryl initiatives prompted and managed by the Chinese government (a single-party authoritarian regime) illustrate such a top-down and authoritarian approach to vision setting. The (technology-driven) Work Station under Deep Sea project, the Five-Year Plans for Solar Energy and New Energy Vehicles are initiatives ruled by the Central Government without any evidence of efforts to build or strengthen the legitimacy of their overall objectives. Citizens were considered at most as potential consumers to be encouraged, via dedicated dissemination activities, to purchase the innovative solutions.

In sum, the category of missions for which vision and objectives have been set without foreseeing any mechanism for citizen involvement is particularly varied and heterogeneous. Evidence has nevertheless been found that there are several cumulative reasons to limit the communication and consultation processes to experts only, while explicitly excluding citizens. These top-down approaches in vision-setting are justified by the fact that the decision-makers do not seek to legitimise the targeted problems (output legitimacy) and because of the way in which these problems were selected (input legitimacy). These missions are defined by decision-makers who are not, or do not feel, accountable to public needs, or consider only scientific and technological dimensions, whose relevance may be estimated without the participation of citizens. Input legitimacy is neglected because of cultural factors and the non-democratic nature of the decision-makers.

\subsection{INFORMATION SHARING TO STIMULATE BUY-IN}

Most case studies gathered evidence of actions undertaken to inform relevant stakeholders and the public at large on individual mission-oriented R\&l initiatives. Communication consists of the activities conducted to diffuse information on the rationales, implementation modalities and impacts of these initiatives. It pursues two interlinked objectives: to raise the public awareness of problems and to demonstrate the relevance of the (policy) interventions thereby stimulating buy-in. In such circumstances, citizens are passively involved to ensure (ex post) the legitimacy of decisions - already taken - on the missions to be pursued. The most commonly employed communication channels are dedicated websites, events (including conferences and workshops), social media, and education programmes. 
The diffusion of information on policy interventions is a practice observed in various initiatives. However, three groups of mission-oriented RGI initiatives can be identified among those that involve citizens only through information-sharing activities.

The first category of mission-oriented Ryl initiatives involving citizens exclusively through communication activities includes initiatives, whose mission is mainly of a technological or scientific nature, but with a political dimension. The legitimacy-building process that is perceived required in these instances is interpreted as bidirectional. On the one side, visions are considered legitimate because they were decided by legitimate decision-makers. On the other side, their popular support enhances, in return, the legitimacy of their decision-makers. Two particularly illustrative case studies are the US Apollo project with its goal of landing a man on the moon and returning him safely to the earth, and the British-French Concorde project to develop supersonic air transport. Despite their objectives to accelerate the development of new technologies, both were given high visibility in media (e.g. the live broadcast of Neil Armstrong from the Moon) and policy discourse. Besides its strategic importance in the then geopolitical context, the Apollo project had a high propaganda value and was aimed at demonstrating to the US citizens the national scientific and technological leadership. Reflecting its political dimension, President Kennedy asked for exploring different options for amendment when criticisms raised. Similarly, in the Concorde project, despite early reservations that investments would have zero or low return, the British government maintained its commitment, mainly for political reasons, among which avoiding the further reduction of the popular support for the government.

The second category of mission-oriented Rql initiatives in which citizen engagement is limited to communication activities and information sharing includes those that consider the perspective of citizens in the vision-setting process, to the extent that the missions relate to problems for which a consensus among citizens is assumed to exist. This approach is observed in situations of a shared sense of emergency in the aftermath of catastrophic events. Citizens are perceived highly likely to consider legitimate any policy interventions designed explicitly to solve a problem that affects most of them and may threaten their safety and/or wellbeing. Communication activities are conducted in order to maintain or even strengthen this initial level of legitimacy (guaranteed by the sense of emergency) to forestall any later loss of popular support and societal acceptance. An example can be found in the initiative taken by the Italian authorities to protect the Venetian lagoon, which is regularly exposed to exceptional tides (the so-called 'acqua alta') and floods with frequency and intensity increasing in recent years ${ }^{7}$. The MOSE project (Italian: MOdulo Sperimentale Elettromeccanico) aimed at the development of technologies for the protection of Venice and other cities in the lagoon from floods and other exceptional tides without affecting the economic activities of the commercial harbours. This initiative presents no evidence of any sort of active engagement of citizens in the decision on its vision. It was assumed that the mission would be considered legitimate by the inhabitants of the lagoon because of their vulnerability to this type of natural disaster.

The third category of mission-oriented R\&l initiatives involving citizens in the selection of missions only via information-sharing actions consists of initiatives conducted by private foundations. As decisionmakers are not elected officials in these cases, it could be expected that low efforts would be made to strengthen the legitimacy of decisions on the missions to pursue. However, some initiatives appeared to be very active in communicating to the large public, as their level of legitimacy has a direct impact on the success of their implementation. Indeed, they may partly rely on private donations (from individuals) and crowdfunding as well as volunteer work, and therefore on their capacity to convince citizens that they can contribute to legitimate missions (linked to the common good) through their financial and in-kind support. Making private and close connections between individuals' concerns and the problem to be solved and, by doing so, building or strengthening (ex post) the legitimacy of the concerned mission-oriented Ryl initiative are assumed to be among the most effective ways to steer citizens in that direction. For instance, the Ocean Cleanup initiative aims at preventing, extracting and intercepting the plastic pollution of oceans. Its wide visibility is ensured by large media coverage as well as its active presence on social media. Information on the causes of plastic pollution is disseminated via the website of the Foundation, which is highly dependent on individual contributions. This strategy contributes to raising public awareness of this problem and the (urgent) need to tackle it.

The legitimacy-building processes within these three categories of mission-oriented R\&I initiatives show similar patterns. Citizens are involved in building the output legitimacy of these mission-oriented Rql initiatives, as information shared with them aim to demonstrate the accuracy and magnitude of the problems to be solved. However, citizen engagement is not seemingly perceived as a relevant criterion in input legitimacy: decisions are made by legitimate decision-makers acting for the purpose of the national pride and global leadership or by private foundations, whose legitimacy does not derive from any popular election. Some missions relate to urgent societal needs that require a swift reaction of decision-makers. In such circumstances, it would be hardly feasible to mobilise citizens and consult them quickly enough. The definition of the vision is therefore made in a top-down manner and is justified afterwards through communication activities.

\subsection{PARTICIPATORY INVOLVEMENT}

Very few of the missions analysed include evidence of some degrees of citizen participation in the selection of the missions to be pursued. The most common way is through public consultations, whereby decisionmakers ask citizens about their views on broad challenges or problems prior to designing policy interventions. This process is controlled and coordinated by the relevant public authorities, which decide on the issues on which citizens provide their feedback and on the procedures for this purpose. Even though public consultation engages more than information sharing, it cannot be yet considered as a genuinely active participation in the policy-making process, especially when the general public is involved late in the decision-making process and is asked to reflect on proposals already developed by policy-makers.

In the mission-oriented RYI initiatives considered, public consultations are organised in different manners, which affect the degree of citizen involvement and the level of openness of the policy-making process to externals inputs. Some initiatives remain open to (spontaneous) feedback and contributions from a wide range of actors, including individual citizens as well as representatives of industry, civil organisations or academia. For instance, feedback collection mechanisms, via public surveys, consultation webpages and interactions with public administrations through social media accounts, contributed to setting the objectives of the Finnish Bioeconomy Strategy. Open consultation tends nevertheless 
to favour the most vocal individuals, who usually have the knowledge to effectively engage in the decision-making process and the ambition to put their problems onto the policy agenda. Public consultations can be also organised by means of interviews and working groups composed of specific actors (including citizens and civil organisations) who have been identified by the decision-makers. For instance, citizens and other stakeholders were involved in Societal Advisory Boards for providing advices on relevant vision and objectives for the Dutch water management strategy to be implemented via the Delta Programme. Whereas open consultation may result in very low or no contribution, interviews and working groups can guarantee some bottom-up contribution to policymaking. Furthermore, the competent public authorities may define criteria for the selection of their participants, such that representativeness is guaranteed and that the voice of citizens is not captured by groups pursuing their own agenda.

Consultation mechanisms were set in mission-oriented R\&I initiatives which are diverse in terms of the nature of the missions (either very scientific and technologic or rather transformative and societal), the type of challenges tentatively addressed (food, agriculture, bio-economy, environment, transport, health, etc.) and the level of policy intervention (supranational, national, local). Nevertheless, three groups of missionoriented $R g l$ initiatives in which citizen engagement is perceived particularly relevant can be identified.

Firstly, practices of vision-setting engaging citizens appear to be particularly relevant in initiatives aimed at solving important societal challenges, as the general public is assumed to be the best placed to identify and characterise the most relevant problems in this respect. For instance, the Clean Air London initiative, which aims at reducing air pollution in the city and at improving thereby well-being and quality of life of its inhabitants, set up mechanisms to collect feedback and suggestions from Londoners and to enable them to interact with the local administrations. Nevertheless, these mechanisms include surveys which were launched late in the decision-making process and aimed more at ensuring popular support for the initiative than at empowering citizens and fully engaging them in setting its vision.

Public consultation is also employed when the vision and objectives are established in the first place by the competent policy-makers, and are subsequently submitted to a panel of actors, including citizens and other types of stakeholders, for their refinement. For instance, to set the objectives of the Luxembourg 3rd Industry Revolution strategy, the initiators set up thematic working groups composed of more than 300 stakeholders, including companies, local administrations and civil society organisations. Their mission was to translate the concept of 'Third Industrial Revolution' into the Luxembourg context: this mainly refers to a transition of economic systems towards peer-to-peer models relying on the generation, distribution and use of renewable energy. The working groups identified and analysed ongoing trends and defined accordingly feasible and consistent objectives. Luxembourg residents were thereby given the opportunity to take part in the design of this transformative initiative.

Finally, where citizens can autonomously organise to trigger a specific policy which responds to a pressuring societal demand, traditional policy-makers might employ participatory schemes to regain control over the policy-making process and handle it for their own benefits. The collected evidence suggests that this situation may occur only in democratic communities whose social actors possess a fair awareness of the functioning of the policy-making process and demonstrate the capacity to prompt the introduction of societal demands in the public policy agenda. Provided that citizen movements are not seen as endangering the current balance of power or hampering the stability of the community, the traditional policy-makers might consider them as opportunities to (further) legitimise their actions. Consequently, also in this particular case, the decision-makers might attribute to the citizens the capacity to participate in setting the vision for mission-oriented R\&l initiatives. An example of this case is the German Energiewende initiative, which consists in a long-term strategy for the development of a low-carbon energy system based on renewable energy and energy efficiency. The development of this mission would have not been possible without the long-standing activism of grassroots green movements advocating for energy transition policies and the phasing out of nuclear power plants. At first, policymakers underestimated the sense of urgency felt by the German citizens in regard to a green transition over decades, until the Fukushima nuclear accident convinced them to steer this long-date public movement in their favour. Participatory schemes were then not simply strengthened and institutionalised, but even encouraged and multiplied. Such shift in policy produced one of the most emblematic examples of citizen involvement in setting the goals and in designing the policy instruments of an mission-oriented initiative.

In regard to the level of legitimacy, the engagement of citizens in setting the vision of mission-oriented R\&l initiatives via dedicated public consultations and other participatory mechanisms ensures first and foremost their output legitimacy. Furthermore, it demonstrates that traditional policy-makers are increasingly - but still marginally - attentive to input legitimacy. Citizen engagement in the decision-making process is interpreted as being not aimed only at ensuring that the ultimate decision will be in line with societal expectations and will have popular support. It can also contribute to building a policy discourse justifying the pursued missions by referring explicitly to the public participation mechanisms employed for their definition. The analysis of the considered case studies suggests that public consultations organised the earliest stages in the decision-making process are nevertheless those that are the closest to genuine participation of citizens. The general public may be asked to contribute directly to the refinement of missions that were broadly defined by policy-makers, or to express their support to (rather elaborated) proposals of missions and objectives. However, in most cases, citizens are not asked to define, through any type of participatory process, which missions would be the most relevant in their views. Citizens are rather expected to give feedback on top-down defined proposals. Finally, in few instances, policy-makers may decide to translate problems already identified by grass-roots movements into well-defined policy interventions. By putting these problems onto the policy agenda, traditional policy-makers similarly ensure that the mission-oriented R\&l initiatives prompted by autonomously organised groups of individuals are considered legitimate. 


\begin{tabular}{|c|c|c|c|c|}
\hline \multirow[t]{2}{*}{$\begin{array}{l}\text { Type and means of } \\
\text { citizen engagement }\end{array}$} & \multirow[t]{2}{*}{$\begin{array}{l}\text { Main observed features of } \\
\text { missions }\end{array}$} & \multirow[t]{2}{*}{ Rationale for the selected degree of citizen involvement } & \multicolumn{2}{|c|}{$\begin{array}{l}\text { Consideration for legitimacy- } \\
\text { building }\end{array}$} \\
\hline & & & Input & Output \\
\hline $\begin{array}{l}\text { NO ROLE } \\
\text { No instrument }\end{array}$ & $\begin{array}{l}\text { Missions } \\
\text { - with high technological } \\
\text { component, } \\
\text { - whose initiators lack culture } \\
\text { and practices of citizen } \\
\text { engagement, } \\
\text { - implemented in non- } \\
\text { democratic regimes. }\end{array}$ & $\begin{array}{l}\text { - Lack of responsiveness of policy-makers to public needs and demands. } \\
\text { - No valuable contributions expected from citizens. } \\
\text { - High reliance on experts, users and industry stakeholders. } \\
\text { - Fear of disruptive effects of citizen engagement on policy-making. }\end{array}$ & NO & NO \\
\hline $\begin{array}{l}\text { COMMUNICATION } \\
\text { Exclusive reliance on } \\
\text { communication tools: } \\
\text { Dedicated websites } \\
\text { Events (conferences, } \\
\text { workshops) } \\
\text { Social media } \\
\text { Education programmes }\end{array}$ & $\begin{array}{l}\text { Missions } \\
\text { - related to societal challenges } \\
\text { but initiated by private } \\
\text { actors, } \\
\text { - with a high technological } \\
\text { component and a major } \\
\text { political dimension, } \\
\text { - related to urgent societal } \\
\text { needs. }\end{array}$ & $\begin{array}{l}\text { - Influence of the degree of popular support on the successful implementation } \\
\text { of missions. } \\
\text { - Need to maintain the initial level of legitimacy throughout the policy cycle. } \\
\text { - Intertwined legitimacy of policies and their initiators. } \\
\text { - Trade-off between swift policy reactions to urgent needs and openness of } \\
\text { policy-making to public participation. }\end{array}$ & NO & YES \\
\hline $\begin{array}{l}\text { PARTICIPATION } \\
\text { Public consultations } \\
\text { Interviews } \\
\text { Working groups } \\
\text { Surveys } \\
\text { Social media } \\
\text { Public Meetings } \\
\text { Stakeholder Forums }\end{array}$ & $\begin{array}{l}\text { Missions } \\
\text { - with anticipated important } \\
\text { - bocietal impacts, } \\
\text { broadly predefined and in } \\
\text { need of refinement, } \\
\text { defined by citizens and } \\
\text { whose translation into the } \\
\text { policy agenda serves the ac- } \\
\text { tions of the policy-makers. }\end{array}$ & $\begin{array}{l}\text { - Influence of the degree of popular support on the successful implementation } \\
\text { of missions. } \\
\text { - Perception of citizens as knowledgeable and capable of participating in } \\
\text { policy-making. } \\
\text { - Democratic and transparent functioning of public administrations. } \\
\text { - Need to develop policy discourse justifying policy interventions. }\end{array}$ & YES & YES \\
\hline
\end{tabular}

Table 1: Elements of citizen involvement and consequence on legitimacy

\section{PERCEIVED CHALLENGES IN THE ENGAGEMENT OF CITIZENS IN VISION-SETTING}

Interviews and a workshop collected the views from RYl actors and help flesh out the reasons of the resistance of policy-makers against further public participation in policy-making, and the modalities in which participation might take place.

\subsection{WHY SHOULD POLICY-MAKERS INVOLVE CITIZENS?}

It is widely admitted that all individuals should be given the opportunity to reflect on the relevance of policy interventions implemented in their community, and particularly on the direction given to missionoriented Ryl initiatives. Such positive opinions towards citizen involvement are mainly underpinned by the assumptions that private organisations and the traditional policy-makers may overlook societal needs while pursuing ambitions often related instead to their own needs; and that citizens have a better understanding than these actors about the most significant challenges to their communities. Furthermore, public participation in policy-making can increase the stability and the legitimacy of policy decisions and the level of transparency of decision-making processes. It may also contribute to making citizens feel responsible for the formulation and design of policies, while curbing the eroding of their trust in democratic systems. Finally, the consulted stakeholders advocating for public participation in decision-making refer to past experiences (e.g. the Irish Citizens' Assembly set up in 2016 to consider the most important issues of the country) to show that, if individuals are trained to effectively take part in participatory mechanisms and informed on the characteristics of the societal challenges, they might demonstrate abilities to grasp complex issues and make relevant policy proposals.

On the contrary, other consulted stakeholders express some reserve in respect to the engagement of citizens in decision-making, particularly in its initial steps, contending that it should be avoided, if not forbidden, and that other types of stakeholders with a better understanding of the challenges to be addressed (including experts and users) have more valuable inputs to bring in the policy-making process. In addition, citizens do not have the mandate nor the capacity to fully understand, represent and elaborate on the societal demands of their community. Because mechanisms for public participation may shed light on discrepancies between citizens and other stakeholders in terms of degree of participation in policy-making, they can also affect the community cohesion. Furthermore, citizens might not be aware of the complexity of the policy cycle to make relevant contributions, especially in countries or regions where mainstream media have a strong influence on their level of understanding of ongoing policy discussions. Social media similarly raise concerns in this respect, as they allow users to favour some information sources while outweighing others for any apparent sensible reason.

In the context of growing populism across Europe, consulted stakeholders worry that mechanisms for public participation in vision-setting divert policy decisions from the missions that are the most likely to accelerate system transformations for solving societal challenges. Because 
those missions may have disruptive (and negative) effects in the short term, citizens may be reluctant to fully support them. Moreover, the participation of citizens in the decision on missions is feared to benefit only easily understandable or 'fashionable' sciences or industries, i.e. those benefitting from high popularity and media coverage.

Finally, some actors are concerned that citizen involvement would be infeasible on practical terms. Mechanisms which are conceived to involve on a regular basis multitude of individuals are costly and their funding too difficult to be viable in the long run. An extra layer of complexity is added by the extreme variety of opinions on a number of issues which makes the finding of a consensus even more difficult.

\subsection{WHICH KIND OF INDIVIDUALS (OR GROUPS OF IN- DIVIDUALS) SHOULD BE INVOLVED?}

Citizens are perceived in competition with other categories of stakeholders in the policy-making process, especially with experts, users and civil society organisations.

In comparison with citizens, experts encompass all individuals with relevant and recognised knowledge in relation to the challenges to be tackled as well as the expertise and experience necessary for suggesting suitable, relevant and feasible answers to the identified problems ${ }^{8}$. Furthermore, experts may be assumed to be more likely to understand the specificities of the policy-making process. The expertise of these individuals and organisations can serve in crucial steps, including the definitions of the scope of the missions and of quantifiable and attainable objectives. For instance, in the Indian Electric Mobility Plan, the government decided to leverage on the participation of transport and automobile stakeholders which have specific interests in the development of the electric vehicle industry.

Some mission-oriented R\&I initiatives attempted to use the contributions from both experts and the general public in a complementary way. For instance, in several of the analysed case studies, the feedback of citizens was used to reflect on the directions identified, in a first time, by individual experts. The EU Human Brain Project adopted this kind of approach: at first, scientists and industry representatives were asked to propose a set of projects; only in a second moment, citizens were engaged to verify the socio-economic and ethical dimensions of the selected proposals and validate the goals of the proposed projects.

What is mostly argued is nevertheless the rationales for involving citizens instead of stakeholders or experts, and whether the decisionmakers should listen to the general public without mediation by any intermediate body and the support of skilled professionals. In the views of governmental agencies and the scientific community, individuals may have some understanding of the societal challenges, but clearly lack the knowledge required to solve them. On the contrary, some not-for-profit organisations argue that citizens, in comparison with experts, have a holistic vision much more focused on the future conditions of the next generations than on the scientific and technological challenges.

Citizens are also often confused and substituted (in the policy-making process) with users. However, while the former are defined in respect to their belonging to specific (social) communities, the essential feature of the latter is being economic and (demand-side) market actors integrating goods and services into their economic activities (by consuming or employing them) in order to obtain some benefits, including the solving of specific problems. Users are considered to hold specific knowledge that relates to their practices and habits and that allows to determine the feasibility of the orientation of R\&I initiatives (especially when they are mainly aimed at the achievement of ambitious scientific, technological or economic challenges) and whether new goods and services are ready to be used. Therefore, the main rationale for user involvement in policymaking is to ensure that the vision is reachable and that the solution to be developed, for that purpose, could be used and diffused at a sufficient pace. Without diminishing this argument, civil society organisations claim that it cannot justify that users are involved in the place of citizens to decide the visions for mission-oriented R\&l initiatives.

The particular role of the general public is indeed to consider the relevance of missions against societal values that are deemed of importance in their community. For these reasons, communication and dissemination activities should be clearly delineated, with the latter aimed at accelerating the uptake of (new) goods and services and not at raising public awareness of the targeted problems. This is the reason why the large events such as those organised in the Chinese New Energy Vehicle initiative for demonstrating newly developed electric vehicles are seen as targeting potential purchasers instead of involving the public at large, and having no influence on the legitimacy of mission-oriented Ryl initiatives.

Given that all individuals are inevitably part an established community and jointly constitute the civil society, all the organisations that are made of individual volunteers have in common the aspiration of representing "a wide range of interests and ties" (OECD, 2006). However, the participation of civil society organisations in policy-making occurs differently than citizen involvement. In the first place, civil society organisations tend to be organised in a complex structure, with allocated responsibilities to group of individuals who are the real interlocutors vis-à-vis decision-makers. Secondly, they have their own communication channels and independently implement their outreach strategies. In the third place, no civil society organisation can claim to represent all the positions of their members and volunteers. They express official positions, which may be the result of internal mediation and compromise.

Moreover, there is a clear tendency in each organisation to focus on a theme or a set of issues, and to unavoidably advocate for the specific interests of limited groups of citizens. For the same reason, their involvement may lead to an excessive politicisation and polarisation of the policy-making process. Despite these concerns, the evidence collected in case studies, such as in the French Agriculture-Innovation 2025 strategy, suggests that some policy-makers prompt the participation of civil society organisations, like family associations, when in need of enlarging their legitimacy.

\subsection{WHICH MODALITIES OF CITIZEN INVOLVEMENT?}

Once citizens are recognized having a specific role in the design of mission-oriented R\&l, policy-making procedures must adapt to allow their involvement. One of the few points on which most consulted stakeholders agree is that a fully bottom-up process is neither feasible nor advisable. Traditional policy-makers should not be excluded from vision-setting and the design of mission-oriented Rql initiatives, as they are the most capable actors to ensure policy coordination. The governance of missionoriented R\&l initiatives should instead rely on a multi-actors model where participants tend to complement, but do not substitute, each other.

Very few consulted stakeholders support the idea to create a dedicated and permanent body in charge of ensuring that citizens are involved in the general policy-making process. It is instead contended 
that existing institutions would be better positioned to translate popular preferences for specific challenges into concrete mission-oriented R\&l initiatives. However, they would need to change their functioning by integrating citizens to their decision-making process. A solution is the establishment of multi-stakeholders groups with the mission to formulate recommendations to bodies in charge of taking decisions, such as the National Cancer Advisory Board (NCAB), which was established in 1971 to ensure the implementation of the War on Cancer initiative, and which contributed to the research plan for the Cancer Moonshot strategy. Public participation in decisions on the visions for mission-oriented R\&I should rely, where possible, on existing practices of citizen engagement in the functioning of public institutions, in order to avoid having disruptive effects and inducing too high costs to public administrations.

Special attention should be paid to the criteria for the selection of the citizens authorised to participate in the vision-setting for missionoriented R\&l initiatives. A general principle should be that the selection should be balanced and avoid, where possible, organisations which may capture the voice of the general public to push forward their own agenda. However, institutional arrangements and adaptation of consultation tools for citizen engagement in decision-making will induce costs, as many consulted stakeholders highlighted. This is even more expected in the case of mission-oriented RGI orchestrated at the EU level, as such practices do not exist yet and may face linguistic and cultural barriers.

\section{CONCLUSIONS}

This research collects evidence and demonstrates that practices of citizen engagement in setting the vision for mission-oriented R\&l initiatives are barely developed. Even though Horizon Europe aims to give them a renewed impetus, their diffusion might be hindered by resistance observed among a large range of $R \& l$ stakeholders. Therefore, this research highlights the need to promote new practices within the policy-making process in order to promote, facilitate and ensure the engagement of citizens in the decision on the missions and thereby improve both their output and input legitimacy, the latter being still rarely considered.

Citizen engagement in policy-making may contribute to solving the disenchantment many citizens currently perceive with the EU institutions. Mechanisms for public participation in decision-making are not aimed at replacing representative democracy, but instead at complementing it. They rely on the observations that the citizens participating in the policy-making process might feel more "committed" and become able to make well-grounded priority-setting. If involved in the policy-making at an early stage, they can also improve their understanding of how public institutions work. Ultimately, the citizens' renewed feeling of responsibility for, and commitment to, the general interest of their community may reduce the distrust against representative democracy that jeopardizes the stability of institutions.

All these arguments are particularly valid for the EU institutions, as they are seemingly the most affected by the growing scepticism about the course of the traditional policy-making process. Eurosceptic feelings have strengthened and gained ground at a high pace over the past ten years in the founding and in the newer Member States, while the UK voters have voted to leave the European Union under the influence of nationalistic propaganda. In such an alarming context, the EU policymakers must curb the perceived widening of the gap between EU institutions and the European citizens and to renew the decision-making processes in order to engage the general public in shaping the future of its policy interventions.

Since mission-oriented R\&l initiatives are essentially aimed at solving problems that will help tackle pressing societal, economic, scientific and technological challenges, they are easily understandable by the general public and are conveniently communicable and justifiable in the public eyes. If handled correctly, missions conceived with citizen involvement will therefore contribute to increasing the legitimacy of the EU in R\&l policy and possibly in other policy domains. Additional efforts for involving the general public in the definition of missions may help further reduce the perceived distance between citizens and the EU institutions. However, this requires the promotion of new practices within the EU policy-making process without lengthening it and increasing its costs (and while abiding by the institutional framework laid down by the Treaties).

Public consultation mechanisms have already demonstrated being valid and important means to ensure output and input legitimacy. The EU policy-makers may rely on these existing practices, enlarge their scope and scale them up at the EU level while overseeing their implementation in Member States. Moreover, further steps towards a more participative decision-process can be designed and implemented on the strengths of past experiences (such as the past Interactive Policy Making mechanism) and in view of the practices currently implemented and for which the European Union is advocating (notably, in the area of e-Governance). By considering the controversy that a suggestion for changing the current decision-making procedures may engender among the Member States and EU bodies, such attempts can be delimited, in a first time, to the field of R\&I policies and initiatives, and, more specifically, to the mission-orientated pillar in Horizon Europe. Another possibility to ensure bottom-up participation in decision-making, as noted by several interviewees, are the platforms established for the definition of the Smart Specialisation Strategy ${ }^{9}$. These could be revived and used to involve the general public at a regional level, by giving the opportunity to define missions capable of meeting the needs of local communities. In addition to these options, civil society organisations suggest the establishment of "Citizens Conventions", whose design and functions may address the challenges that this research identified ${ }^{10}$.

The main issues with these tentative mechanisms relate to the substantial lack of experience in handling them in several Member States or at a transnational level. Moreover, even if correctly implemented, they would need to collect the opinions of citizens who are exposed to a wide variety of challenges or to similar ones but at varying intensities (e.g. ocean pollution may be less a concern for Central European countries). Citizen involvement mechanisms would have to cope also with the challenges traditionally faced by all sorts of exercises implemented at the EU scale, i.e. the presence of different political cultures and multilingualism. However, while not dismissing their importance, these challenges could be regarded as the raison d'être of an intergovernmental organisation such as the European Union and should not be considered as a hindrance to more participatory and democratic policy-making processes. On the contrary, given that missions aim at solving challenges which often have transnational impacts, the coordination of mission-oriented RYI should be guaranteed at EU level. As a consequence, the institutions of the European Union will be the best placed to find and implement renewed methods and practices to engage citizens in setting the missions to orient R\&l policy. 


\section{REFERENCES}

Boedeltje, M. and Cornips, J. (2004). Input and output legitimacy in interactive governance. Presented at the NIG Annual work conference, Rotterdam.

Boon, W. and Edler, J. (2018). Demand, challenges, and innovation. Making sense of new trends in innovation policy. Science and Public Policy, 45(4), 435-447. https://doi.org/10.1093/scipol/scy014.

Borrás, S. and Edquist, C. (2013). The choice of innovation policy instruments. Technological Forecasting and Social Change, 80(8), 1513-1522. https://doi.org/10.1016/j.techfore.2013.03.002.

Bugge, M. M., Coenen, L. and Branstad, A. (2018). Governing sociotechnical change: Orchestrating demand for assisted living in ageing societies. Science and Public Policy. https://doi.org/10.1093/scipol/scy010.

Bush, V. (1945). Science The Endless Frontier (A Report to the President). Washington D.C.: United States Government Printing Office.

Dahl, R. A. (1998). On Democracy. New Haven: Yale University Press.

Edquist, C. (2011). Design of innovation policy through diagnostic anaIysis: identification of systemic problems (or failures). Industrial and Corporate Change, 20(6), 1725-1753. https://doi.org/10.1093/icc/dtr060.

Flanagan, K. and Uyarra, E. (2016). Four dangers in innovation policy studies - and how to avoid them. Industry and Innovation, 23(2), 177188. https://doi.org/10.1080/13662716.2016.1146126.

Jagers, S., Matti, S. and Nordblom, K. (2016). How Policy Legitimacy Affects Policy Support Throughout the Policy Cycle. OoG Working Paper Series, 2016(15).

JIIP, Joanneum Research, Tecnalia, TNO, VTT and DTI. (2018a). Mission-oriented research and innovation: Inventory and characterisation of initiatives. Luxembourg: Publications Office of the European Union.

JIIP, Joanneum Research, Tecnalia, TNO, VTT, DTI and VVA. (2018b). Mission-Oriented Research and Innovation: Assessing the impact of a mission-oriented research and innovation approach. Luxembourg: Publications Office of the European Union.

Kingdon, J. W. (1984). Agendas, alternatives, and public policies. Boston: Longman.
Laranja, M., Uyarra, E. and Flanagan, K. (2008). Policies for science, technology and innovation: Translating rationales into regional policies in a multi-level setting. Research Policy, 37(5), 823-835. https://doi. org/10.1016/j.respol.2008.03.006.

Nelson, R. R. (2011). The Moon and the Ghetto revisited. Science and Public Policy, 38(9), 681-690. https://doi.org/10.1093/scipol/38.9.681.

OECD. (2001). Citizens as partners: information, consultation and public participation in policy-making. Paris: OECD Publishing.

OECD. (2006). Applying Strategic Environmental Assessment: Good Practice Guidance for Development Co-operation (DAC Guidelines and Reference Series). Paris: OECD Publishing.

Scharpf, F. W. (2006). Problem Solving Effectiveness and Democratic Accountability in the EU. Reihe Politikwissenschaft, (107), 43.

Vigoda, E. (2002). From Responsiveness to Collaboration: Governance, Citizens, and the Next Generation of Public Administration. Public Administration Review, 62(5), 527-540. https://doi.org/10.1111/15406210.00235

Wallner, J. (2008). Legitimacy and Public Policy: Seeing Beyond Effectiveness, Efficiency, and Performance. Policy Studies Journal, 36(3), 421-443. https://doi.org/10.1111/j.1541-0072.2008.00275.x.

Weber, K. M., and Rohracher, H. (2012). Legitimizing research, technology and innovation policies for transformative change: Combining insights from innovation systems and multi-level perspective in a comprehensive 'failures' framework. Research Policy, 41(6), 1037-1047. https:// doi.org/10.1016/j.respol.2011.10.015.

\section{AUTHORS}

\section{JULIEN CHICOT AND ALBERTO DOMINI}

The Joint Institute for Innovation Policy (JIIP)

Boulevard de la Plaine 9, 1050 Brussels, Belgium

E: julien.chicot@jiiip.eu

E: alberto.domini@jiip.eu

ORCid number of Julien Chicot: https://orcid.org/0000-0002-8498-956X

\section{KEYWORDS:}

Mission-oriented R\&l; Legitimacy; Citizen involvement

2 Even though this sample was aimed at being balanced, it does not have the ambition to be representative. In consequence, the outcomes of the case studies cannot be subject to statistical generalisation.

3 These case studies can be consulted on the online JIIP Global Observatory of Mission-Oriented R\&I: www.jiip.eu/mop

$4 \quad$ In total, 40 organisations were interviewed. They were asked generic questions in relation to the characteristics and potential impacts of mission-oriented Ryl initiatives.

5 The preliminary findings of both studies were presented to 20 experts and relevant stakeholders during a workshop co-organised with the European Commission in February 2018. A session was dedicated to the engagement of citizens in mission-oriented R\&l initiatives.
} 
ISSUE 47| MAY $2019 \quad 61$

inotes 